\title{
ENCUADERNACIONES RENACENTISTAS DE LA BIBLIOTECA DEL SEMINARIO METROPOLITANO DE BADAJOZ
}

\author{
José Luis Herrera Morillas* \\ Facultad de Biblioteconomía y Documentación. Universidad de Extremadura.
}

\begin{abstract}
Resumen: Localización, recopilación y análisis de las encuadernaciones renacentistas conservadas en la Biblioteca del Seminario Metropolitano de Badajoz. En total se describen 47 encuadernaciones. El punto de partida de este estudio se encuentra en una investigación en curso sobre todas las encuadernaciones de los siglos XVI al XIX de la citada Biblioteca. Para cada encuadernación se elabora un registro que se incluye en esta investigación.
\end{abstract}

Palabras clave: Encuadernación histórica; encuadernación renacentista; libros antiguos; patrimonio bibliográfico en Badajoz.

Title: THE RENAISSANCE BOOKBINDINGS OF THE LIBRARY OF THE "SEMINARIO METROPOLITANO DE BADAJOZ".

Abstract: Location, compilation and analysis of the Renaissance bookbindings of Library of "Seminario Metropolitano de Badajoz" (Metropolitan Seminar of Badajoz). In total 47 bookbindings are described. The point of item of this work is in an investigation in process on all the bookbindings of the XVIth to XIXth century of the mentioned Library. For every binding we have elaborated a record that is included in the paper.

Keywords: Historical bookbinding; renaissance bookbinding; rare books; cultural heritage in Badajoz.

\section{INTRODUCCIÓN}

El objetivo de esta investigación ha consistido en localizar y describir las encuadernaciones artísticas de estilo renacentista que se conservan en el fondo antiguo de la Biblioteca del Seminario Metropolitano de Badajoz. Queremos contribuir a poner en valor uno de los principales fondos antiguos de Extremadura y dar a conocer un aspecto desconocido de los libros antiguos conservados en esta Biblioteca: sus encuadernaciones, de las que no existen estudios previos.

Esta Biblioteca tiene su origen en el siglo XVIII. Es fruto de la unificación de fondos de diferente procedencia, entre los que destacan: la biblioteca del primer seminario conciliar, la biblioteca del colegio de la Compañía de Jesús, la librería del obispo o los libros del colegio jesuítico de Higuera la Real.

\footnotetext{
*jlhermor@unex.es

Recibido: 17/05/2011; 2ª revisión: 04/07/2011; aceptado: 28/11/2011.
}

HERRERA MORILLAS, J.L. Encuadernaciones renacentistas de la Biblioteca del Seminario Metropolitano de Badajoz. Anales de Documentación, 2012, vol. 15, nº 1. http://dx.doi.org/10.6018/analesdoc.15.1.128311. 
La Biblioteca se ha ido enriqueciendo con el paso del tiempo hasta llegar a nuestros días como la más importante dentro de las bibliotecas eclesiásticas de Extremadura y no superada en sus fondos clásicos por ninguna otra biblioteca extremeña de titularidad civil. Su fondo antiguo (publicaciones anteriores al siglo XX) está formado por unos 11.249 ejemplares (Pérez, 2007). Si le sumamos el fondo moderno la colección está formada por unos 35.000 volúmenes de los que un 15 \% están sin catalogar.

Como muestra de la importancia de este fondo baste decir que más de un centenar de los libros del siglo XVI no se encuentran en ninguna biblioteca española. Entre los fondos valiosos citamos la Biblia Regia de Arias Montano; la edición “princeps” romana de El Fisiólogo de San Epifanio, único ejemplar existente en España; los Sermones de San Vicente Ferrer (1509), la Catena aurea de Santo Tomás de Aquino (1520), las Obras de Virgilio (1527), la edición italiana del Orlando Furioso de Ariosto (1556), la edición de 1558 de la Gramática latina de Nebrija, el Catecismo del arzobispo de Toledo Bartolomé Carranza (1558) -uno de los poquísimos ejemplares existentes en el mundo- y la colección de literatura emblemática con al menos el 15\% de los doscientos ejemplares más significativos que se editaron en Europa desde mediados del siglo XVI hasta la decadencia de este tipo de literatura. Como importante ayuda, la Biblioteca cuenta también con todas las fuentes bibliográficas en las que bebieron los libros de emblemas (Virgilio, Ovidio, Horacio, Tácito, César, Séneca, Juvenal; escritores de Historia natural como Aristóteles, Catón, Varrón, Colmuela, más otros escritores medievales) (Tejada, 2007) $)^{1}$.

Una parte de estos fondos conserva interesantes encuadernaciones artísticas. Su valor radica fundamentalmente en la antigüedad de muchas de ellas, datadas en su mayoría desde el siglo XVI en adelante -contando con algún ejemplar de mayor antigüedad-; y en su gran variedad, pues, están representados buena parte de los distintos estilos y periodos cronológicos desde encuadernaciones medievales, renacentistas o barrocas, hasta los diferentes estilos del siglo XIX (románticas, isabelinas, neoclásicas, etc.). Todas ellas con un alto valor artístico. A las que hay que sumar la importante representación de encuadernaciones industriales o de editor fechadas en el siglo XX, consideradas ya como representativas de un periodo de personalidad propia dentro del arte ligatorio.

En España la aparición de la encuadernación renacentista es tardía, hacia mediados del siglo XVI, y sus modelos no imitan a los de otros países (López, 1972, p. 57). Entre las causas se citan: a) el fuerte arraigo de la encuadernación mudéjar y de la tradición de la técnica del gofrado b) el empleo de los motivos decorativos de influencia alemana y flamenca (Miguélez, 2009b, p. 184).

El estilo decorativo propio de la encuadernación renacentista española del XVI es el Plateresco. En él se conjugan la influencia flamenca y alemana, reflejada en la utilización de ruedas como principal elemento decorativo; la tradición clásica renacentista empleada en los motivos de los hierros sueltos y de las ruedas; y el diseño de un tipo de encuadernación denominada "popular", que se caracteriza porque la estructura de la 
decoración de la tapas está formada por recuadros, hexágonos, octógonos, rombos..., construidos con ruedas cuyos motivos grabados van desde los típicos medallones de cabezas, los que se basan en motivos vegetales o de trofeos, típicamente renacentistas, hasta figuras de animales que representan los aludidos motivos populares españoles, dispuestos de forma concéntrica. El espacio libre central se cuaja con hierros sueltos, gofrados o dorados, de distintos motivos tales como animales, florones aldinos, calaveras, jarrones, floroncillos, escudos heráldicos o elementos religiosos... (Enciclopedia de la Encuadernación, 1998, p. 234).

Según Carrión (1994, p. 403-407) la encuadernación renacentista española del siglo XVI se caracteriza por estos rasgos:

- El empleo de la piel de becerro en su color natural o castaño como material más frecuente

- El uso de la rueda como elemento básico para el gofrado

- El uso de hierros sueltos de diferentes y variados motivos (heráldicos, animales, motivos religiosos motivos vegetales, estrellas, conchas, rosetas, pétalos, margaritas, etc.)

- La estructura relativamente uniforme de la composición estampada, utilizando recuadros

- Una mayor atención para el lomo

- El uso del dorado

- El uso del cartón o “papelón” para conseguir tapas y libros más ligeros

\section{METODOLOGÍA}

En primer lugar ha sido necesario realizar un inventario de las encuadernaciones artísticas existentes en la Biblioteca, para lo que no ha existido más opción que realizar un trabajo de campo. Hemos recorrido las estanterías del depósito donde se ubican los libros, visualizándolos y anotando los que tienen encuadernaciones artísticas.

Una vez realizado el inventario se ha procedido a la descripción de cada encuadernación. Para ello se ha elaborado previamente un modelo de registro formado por estos elementos ${ }^{2}$ :

1. Referencia bibliográfica

2. Signatura topográfica

3. Dimensiones de la encuadernación

4. Aspectos técnicos

5. Descripción del estilo artístico y/o ornamentación de la encuadernación

6. Imagen

Para elaborar las referencias bibliográficas (autor, título, lugar de publicación, impresor y año de publicación) se ha utilizado la norma ISBD (A). Hemos partido de los datos bibliográficos que tiene recogidos la Biblioteca, los hemos cotejado con el original y en algunos casos se han hecho las correcciones oportunas cuando ha sido necesario. 
De los aspectos técnicos hemos recogido todos aquellos que se pueden identificar a simple vista: material de la cubierta (piel, pergamino, tela, papel y orfebrería), de las tapas (madera o cartón), características del lomo (forma, nervios, tejuelo), cabezadas, guardas y cierres. Las dimensiones de la encuadernación se corresponden con: largo $\mathrm{x}$ ancho $\mathrm{x}$ grosor en cms. La descripción de la ornamentación se basa en la estructura decorativa, las técnicas y utensilios, y en la decoración de los cortes, cantos y guardas. Así mismo, los conocimientos sobre técnicas y estilos artísticos de las encuadernaciones, también han formado parte de la metodología y han sido fundamentales.

Las encuadernaciones las hemos clasificado teniendo en cuenta los tipos establecidos por Méndez (1994, p. 96-99). Dentro de las encuadernaciones renacentistas distingue dos tipos:

A. Encuadernaciones que tienen como principal motivo decorativo los filetes y florones.

B. Encuadernaciones que emplean como principal motivo decorativo las grecas.

Dentro del primer tipo diferencia:

A.1 Encuadernaciones con filetes y florones. Con estas variantes:

A.1.1 Encuadernaciones decoradas con filetes y florones gofrados

A.1.2 Encuadernaciones decoradas con filetes y florones dorados

A.1.3 Encuadernaciones decoradas con filetes gofrados a los que acompañan florones dorados.

A.1.4 Encuadernaciones decoradas con filetes gofrados y dorados, y florones gofrados y dorados

A.1.5 Encuadernaciones decoradas con adornos de plancha en los ángulos y en el centro

-A.2 Encuadernaciones de lazo

Dentro del segundo tipo establece estas divisiones:

-B.1 Encuadernaciones decoradas con grecas de elementos vegetales

-B.1 Encuadernaciones decoradas con grecas de cabecitas encerradas en óvalos o en círculos

-B.3 Encuadernaciones decoradas con grecas de animales en movimiento o reposo entre elementos vegetales

-B.4 Encuadernaciones decoradas con grecas de arreos militares

A esta clasificación hemos añadido esta variante:

-Encuadernaciones decoradas con otros modelos de grecas

\section{DESCRIPCIÓN DE LAS ENCUADERNACIONES}

Antes de iniciar la descripción de las 47 encuadernaciones localizadas realizamos una breve descripción de las técnicas de decorado con el propósito de hacer más comprensible el estudio y análisis que recogemos de cada ejemplar ${ }^{3}$. 
Las técnicas de decorado de las cubiertas se basan en realizar unos dibujos y adornos empleando unas herramientas de metal llamadas hierros. Hay varios tipos. Los más frecuentes son tres: los hierros sueltos, los hierros de rueda y las paletas. Los hierros sueltos llevan grabados en un extremo el motivo decorativo. Los hierros de rueda (o ruedas) están formados por un disco o cilindro de metal que presentan el motivo grabado en su circunferencia y al girar en torno a un eje permite grabar en menor tiempo una superficie mayor. Las paletas son hierros adaptados específicamente para su aplicación en el lomo del libro.

Estas herramientas se pueden estampar mediante el procedimiento del "gofrado". Se aplican con calor sobre la piel ligeramente humedecida; o mediante el procedimiento del “dorado”; antes de aplicar los hierros hay que fijar láminas de pan de oro a la piel.

Con los hierros se realizan diferentes motivos decorativos. Entre lo más utilizados se encuentran el "filete"; línea recta o curva, de diferente grosor (los de menor grosor se denominan con frecuencia de "hilo fino"). Pueden aparecer solos o agrupados, por ejemplo, en nuestras encuadernaciones abunda el juego de triple filete formado por un filete grueso en el centro y dos más finos. Las líneas pueden ser continuas o discontinuas formando pequeños puntos, guiones, etc.

"Florón": ornamento que representa motivos florales o vegetales más o menos estilizados. En las encuadernaciones recopiladas son frecuentes lo florones de tipo “aldino" formados por elementos vegetales estilizados y líneas curvas. Su nombre procede del impresor veneciano Aldo Manuzio.

En las encuadernaciones de la Biblioteca estudiada los motivos de los hierros son variados. Estos son los que más se han utilizado: hierros de iconografía religiosa (Cordero místico, cruz); de motivos vegetales (florones y flores varias, ramas, bellotas, granadas, flor de lis); de animales (león, león rampante con corona, caballo, águila, delfín, elefante con castillo en el lomo); de figuras geométricas (pequeños círculos, volutas); de otras figuras (jarrón, corazón, corazón atravesado por flechas, sol, sol con rasgos humanos, concha).

"Orla": motivo decorativo que enmarca o rodea una superficie de la tapa. Cuando la orla está colocada muy próxima al borde de la tapa se le puede denominar "bordura”.

“Superlibris”: símbolo, inscripción o blasón que indica una marca de posesión. Situado normalmente en el centro de la tapa. En nuestro estudio se han empleado en varias ocasiones el monograma de Cristo (JHS) acompañado de la cruz y 3 clavos, y en otra un escudo eclesiástico.

Los lomos descritos presentan en prácticamente la totalidad de los ejemplares los nervios salientes (tanto dobles como sencillos). Dejan un espacio entre ellos que se 
aprovecha en muchas ocasiones para decorar en forma de "recuadramiento" o "encasillado" que no es más que un recuadro delimitado por filetes y decorado con florones en el centro y/o en las esquinas. La superficie del nervio se puede decorar encima y los nervios se resaltan en ocasiones delimitándolos con filetes. Los extremos superior e inferior del lomo, llamados zona de cabeza y pie, se decoran frecuentemente con paletas.

Los entrenervios son el lugar elegido para situar los “tejuelos”: rectángulos de piel o tela para indicar el nombre del autor, del título o el volumen. Información que suele ir estampada en dorado.

En nuestra descripción también mencionamos las "cabezadas"; unas trencillas elaboradas con hilos de diferentes colores que bordean el corte de las hojas. Constituyen una prolongación del borde saliente del cartón. Hay diferentes modelos. En nuestros libros la más corriente ha sido la de un solo capitel tejida a mano; los “cortes”; son los bordes exteriores de las hojas del libro. Pueden ir dorados, cincelados (después de dorarlos se perfila un dibujo para puntearlo con un cincel) o pintados; y las "guardas"; folio de protección situado al inicio y al final del volumen, se dobla sobre sí mismo para unir el libro y la tapa.

\subsection{Encuadernaciones decoradas con filetes y florones gofrados}

1. Biblia Sacra. Lugduni: apud Guliel. Rovillium, 1566.

T. 20012.

$40 \times 25 \times 10 \mathrm{~cm}$.

Encuadernación de piel sobre tabla con vestigios de llevar broches.

El lomo va pegado, con 5 nervios, resaltados por triple filete. Los entrenervios llevan un florón en el centro.

Las guardas son de papel verjurado.

Los cortes van coloreados con tinta roja.

Decoración de las tapas. Se inicia con una bordura de ocho filetes de hilo fino. En el interior se intuye (debido al mal estado de conservación) un encuadramiento trazado por ruedas de cuatro filetes de hilo fino. Bordura y encuadramiento se separan por una calle decorada con florones. El centro de la tapa va ornamentado con cuatro florones unidos por el vértice y rodeados de hierros en forma de varilla dispuestos radialmente. Alrededor de los cuales se disponen otros florones de distinto tamaño separados por espacios sin decoración. La misma composición, pero en cuarto de esfera, se dispone en las cuatro esquinas interiores.

2. Biblia sacra. Salmanticae: apud Gasparem à Portonariis suis \& Gulielmi Rouillij Benedictiq[ue] Boierij expensis, 1584 (Ex Officina Ildefonsi à Terranoua \& Neyla, 1585).

T. 22040.

Obra en 2 volúmenes.

$29,5 \times 22 \times 6,5 \mathrm{~cm}$. 
Encuadernación de piel color marrón claro sobre madera. Lleva cierres de metal.

El lomo va pegado y es de 5 nervios dobles, decorados y resaltados por triple filete (más acho el del centro) que se prolonga en las tapas formando triángulos.

Las guardas son de papel verjurado.

Decoración de las tapas. La decoración se inicia con una bordura de filetes de tres hilos, más grueso el central. Le siguen dos rectángulos concéntricos separados por calles vacías. Los rectángulos están formados por un triple filete, más grueso el central. Se incluyen florones en las esquinas exteriores.

El espacio central se decora con un adorno circular formado por cuatro florones (semejantes a los de las esquinas de los rectángulos) unidos por su vértice y cuatro florones de distinto diseño en los ángulos interiores. Unos hierros con la figura del Cordero místico se sitúan en el eje vertical. Se aprecian cuatro florones de distinto diseño repartidos por los lados.

3. Buenaventura, Santo. D. Bonaventurae... Ord. Minorum In Librum sapientiae et lamentationes Ieremiae Prophetae pia et erudita expositio. Nunc primùm post diutinam expectationem in lucem emissa, \& ad ueterum exeplarium fidem per F. Ioannem Balainium Andrium couentualem Franciscanum accuratissimè recognita. Venetiis: apud Franciscum Saluionum, 1574.

T. 22084 / T. 24172

Obra en dos tomos.

17 x 11 x 4 cm. / 17 x 11 x $5 \mathrm{~cm}$.

Encuadernación de piel color marrón claro sobre cartón.

El lomo va pegado, de 3 nervios dobles, decorados y resaltados por triple filete (más acho el del centro) que se prolongan en las tapas formando triángulos. Los entrenervios se decoran con tres florones con motivo de corazón.

Las cabezadas son de un solo capitel, montadas al aire. Van tejidas a mano con hilos de color azul, amarillo y marfil. Están sujetas al libro en diferentes puntos con el hilo de la cabezada.

Las guardas son de papel verjurado.

Decoración de las tapas. Están bordeadas por tres filetes gofrados, más grueso el central. Las esquinas interiores se decoran con cuatro florones aldinos. Una cartela ovalada con el monograma de Cristo, la cruz y los tres clavos se aprecia en el centro de la tapa. Cuatro pequeños florones la rodean en la dirección de los puntos cardinales.

4. Eusebio de Emesa. D. Eusebii Emisseni Homiliae in Evangelia: quae cunctis diebus dominicis totius anni ac feriis quadragesimalibus legi solent...: quibus annecti curauimus eiusdem homilias de praecipuis anni festiuitatibus. Nunc primum in lucem aeditae. Antuerpiae: in aedibus Viduae \& Haeredum Ioan. Steelsium, 1568.

T. 29138.

$16 \times 11 \times 3 \mathrm{~cm}$.

Encuadernación de piel color marrón claro sobre cartón. 
El lomo pegado está formado por 3 nervios dobles, decorados y resaltados con triple filete, más ancho el central, que se prolonga hasta las tapas en forma triangular. Los entrenervios se han diseñado con encasillados formados por un filete y un hierro en forma de flor de 6 pétalos dobles colocado en el centro.

Las cabezadas son de un solo capitel; están montadas al aire; van tejidas a mano y sujetas al libro en diferentes puntos con el hilo de la cabezada.

Las guardas son de papel verjurado.

El corte delantero lleva escritas con tinta ferruginosa estas letras: “Emysen”.

Decoración de las tapas. Están enmarcadas por dos recuadros de tres filetes (más grueso el del centro). Los recuadros están separados por una calle sin decoración. Un rectángulo hace de bordura y el otro delimita un espacio central que se decora con una cartela ovalada. La cartela reproduce el monte Calvario con las tres cruces, flanqueadas por dos árboles y una calavera en el suelo. Dos hierros en forma de rama con tres bellotas se colocan en el eje central, por encima y por debajo de la cartela. Cuatro florones aldinos se aprecian en las esquinas exteriores del rectángulo central.

5. Fulgencio de Ruspe, Santo. Beati Fulgentii ecclesiasticorum veterum doctorum patrum ue nulli non conferendi Opera...: quorum catalogum versa enumerabit pagina: cum indice omnium obseruantione dignorum copioso. Basileae: ex officina Henric Petrina, 1566.

T. 29120.

16 x 11 x $5 \mathrm{~cm}$.

Encuadernación de piel color marrón claro sobre cartón.

El lomo va pegado. Está formado por 3 nervios dobles, decorados y resaltados por tres filetes que se prolongan en las tapas en forma de triángulo.

Las cabezadas son de un solo capitel; van montadas al aire; están tejidas a mano y sujetas al libro en diferentes puntos con el hilo de la cabezada.

El corte delantero presenta en tinta ferruginosa este texto: D. FULGENTI / OPERA.

Las guardas son de papel verjurado.

Decoración de las tapas. Se inicia con una bordura de tres filetes, más grueso el del centro. Le sigue un rectángulo concéntrico realizado con los mismos filetes y separado por una ancha calle sin decoración. Este rectángulo se ornamenta con florones aldinos en las esquinas exteriores. Un hierro con la iconografía del Cordero místico se sitúa en el centro del espacio interior.

6. Lucas, Franciscus. Notationes in Sacra Biblia: quibus variantia discrepantibus exemplaribus loca summo studio discutiuntur. Antuerpiae: ex officina. Christophori Plantini..., 1580.

T. 20079.

$23 \times 17 \times 3,5 \mathrm{~cm}$.

Encuadernación de piel color marrón claro sobre cartón. 
El lomo pegado está formado por 4 nervios dobles, decorados y resaltados por triple filete gofrado (se aprecia con dificultad por el desgaste). Las zonas de entrenervios se decoran con encasillados de doble filete dorado. Llevan en el centro un hierro en forma de flor con tallo y hojas y otros hierros diferentes en las esquinas. El segundo entrenervio presenta un tejuelo de piel color marrón claro con letras doradas del título.

Las cabezadas son de un solo capitel; van montadas al aire; están tejidas a mano con hilos de dos colores (azul y marfil) y se sujetan al libro en diferentes puntos con el hilo de la cabezada.

Las guardas son de papel verjurado.

El corte delantero lleva escritas algunas letras del título con tinta ferruginosa.

Los contracantos presentan un filete gofrado.

Decoración de las tapas. Se inicia con una bordura realizada con dos filetes gofrados, más ancho el exterior. Un adorno a modo de gran florón se coloca en el centro de la tapa. Ha sido estampado en seco. Se aprecian en él unos pequeños hierros que rodean el motivo central.

7. Menezes, Sebastián Cesar de, Obispo de Lisboa. Sugillatio ingratitudinis. [S.l.: s.n., s.a.].

T. 85845.

$24 \times 19 \times 4 \mathrm{~cm}$

Encuadernación de piel color marrón claro sobre cartón. Técnica del gofrado y técnica del dorado.

El lomo pegado está formado por 3 nervios sencillos, resaltados por finos filetes que se prolongan hacia las tapas en forma triangular. Unos florones grandes y dorados se ven en el centro de los entrenervios. Los vestigios de una paleta se aprecian en la zona del pie. Las letras doradas del título, separadas por dobles filetes se disponen en el segundo entrenervio.

Las cabezadas son de un solo capitel; van montadas al aire; están tejidas a mano y sujetas al libro en diferentes puntos con el hilo de la cabezada.

Las guardas son de papel verjurado.

Decoración de las tapas. La decoración está estampada en seco y es muy sencilla. Se inicia con un filete de hilo muy fino que bordea la tapa. Un rectángulo formado por una rueda de un filete de hilo fino aparece en el interior. Cuatro florones lo decoran en la parte exterior de las esquinas. El centro de la tapa se ornamenta con cuatro florones del mismo tipo unidos por los vértices y dos más que se añaden por encima y por debajo formando un adorno de mayor tamaño.

8. Perera, Benito. Benedicti Pererii valentini e Societate Iesu Commentariorum in Danielem Prophetam, libri sexdecim: adiecti sunt quatuor indices... Lugduni: ex Officina Iuntarum, 1588.

T. 22119.

$22 \times 17 \times 5 \mathrm{~cm}$. 
Encuadernación de piel color marrón claro.

El lomo pegado está formado por 4 nervios decorados y resaltados con triples filetes gofrados. Los nervios se prolongan en las tapas formando triángulos. Un hierro en forma de corazón atravesado por dos flechas cruzadas en aspa se coloca en el centro de los entrenervios. El primer entrenervio presenta un tejuelo con letras escritas a mano ilegibles.

Las cabezadas son de un solo capitel; van montadas al aire; están tejidas a mano y sujetas al libro en diferentes puntos con el hilo de la cabezada.

Decoración de las tapas. Se inicia con una bordura de filetes de tres hilos, más grueso el central. Le siguen dos rectángulos concéntricos formados por un triple filete del mismo tipo. Los rectángulos están separados por calles vacías y presentan florones en las esquinas exteriores. El espacio interior lleva una cartela circular en el centro, a modo de superlibris, con el monograma de Cristo, la cruz y los 3 clavos. La cartela está rodeada por una ráfaga. Los mimos hierros del lomo con motivo de corazón se disponen en el eje central por encima y por debajo de la cartela.

9. Suárez, Francisco. Defensio fidei catholicae et apostolicae aduersus anglicanae sectae errores, cum responsione ad apologiam pro iuramento fidelitatis et praefationem monitoriam serenissimi Iacobi Angliae regis. Conimbricae: apud Didacum Gomez de Loureyro academiae typographum, 1613.

T. 52029.

$28 \times 20 \times 7,5 \mathrm{~cm}$.

Encuadernación de piel color marrón claro sobre cartón.

El lomo pegado está formado por 4 nervios dobles, resaltados por tiple filete, que se adentra en las tapas. Un hierro en forma de león rampante con corona se sitúa en el centro de los entrenervios.

Las cabezadas son de un solo capitel; van montadas al aire; están tejidas a mano con hilos de dos colores y sujetas al libro en diferentes puntos con el hilo de la cabezada.

Las guardas son de papel verjurado con algunas anotaciones manuscritas.

Decoración de las tapas. Se inicia con tres filetes, el central más grueso, que bordean la tapa. Dos rectángulos concéntricos realizados con una rueda de tres filetes del mismo tipo y decorados con cuatro florones en las esquinas, por su parte exterior. El centro de la tapa se embellece con un adorno central formado por cuatro florones unidos por el vértice, por encima y por debajo, se sitúan dos hierros de leones rampantes con coronas. También, se incluyen otros cuatro florones en las esquinas interiores del rectángulo central.

10. Tapia, Diego de. Fratris Didaci de Tapia... Ordinis Eremitarum Diui Augustini In tertiam partem Diui Thomae libri duo: vnus de Incarnatione Christi Domini, alter de admirabili Eucharistiae sacramento: adiectus etiam est in fine Tractatus de ritu missae... Salmanticae: ex officina Michaelis Serrani de Vargas, 1589.

T. 46021.

$33 \times 23 \times 6,5 \mathrm{~cm}$.

Encuadernación de piel color marrón claro sobre cartón. 
El lomo va pegado. Está formado por 5 nervios dobles, decorados encima y resaltados por triple filete, más grueso el del centro. Estos filetes se prolongan hacia las tapas formando triángulos. Cada entrenervio lleva en el centro un hierro de un pelícano y otros en forma de florón en los lados.

Las cabezadas son de un solo capitel; van montadas al aire; están tejidas a mano y sujetas al libro en diferentes puntos con el hilo de la cabezada.

Las guardas son de papel reutilizado. Lleva hojas de respeto.

Decoración de las tapas. Es muy sencilla y se inicia con tres filetes (el central más grueso) que bordean la tapa. Dos rectángulos concéntricos formados por una rueda de tres filetes (el central más grueso) se disponen en el interior. Los rectángulos están decorados en las esquinas, por su parte exterior, con cuatro florones. El centro de la tapa está decorado con un hierro de la iconografía del Cordero místico y por dos hierros con la figura de un pelícano, dispuestos por encima y por debajo.

\subsection{Encuadernaciones decoradas con filetes y florones dorados}

11. Agustín, Santo, Obispo de Hipona. Sancti Aurelii Augustini Hipponensis Episcopi Operum tomus quintus: continens sermones ad populum: post Lovaniensium theologorum recensionem correctos denuo ad manuscriptos codices Gallicanos, Romanos, \&c. necnon ad editiones antequiores \& castigatiores. Parisiis: excudebat Franciscus Muguet..., 1683.

T. 29140G.

Esta obra incluye 15 tomos. La descripción la basamos en el tomo V.

$45 \times 30 \times 6 \mathrm{~cm}$.

Encuadernación de piel color granate sobre cartón.

El lomo tiene 6 nervios dobles y va pegado. En el conjunto de los 16 tomos hay dos modelos: un modelo presenta los nervios decorados encima con paletas de hojas y los entrenervios con encasillados formados por un rectángulo, realizado con un filete de un hilo que en los lados añade otro de dientes de ratón. El espacio interior se rellena con un florón en el centro, hierros de ramas en las esquinas y hierros de pequeños círculos por el resto del espacio. Uno de los primeros entrenervios lleva letras doradas del nombre del autor y del título, enmarcadas por filetes. El siguiente entrenervio presenta el número del tomo. Los extremos de cabeza y pie están ornamentados con paletas. El otro modelo tiene decorados el interior de los encasillados con un florón de tres flores en el centro y una composición de pequeños hierros adaptados a los ángulos de las esquinas.

Las cabezadas son de un solo capitel; van montadas al aire; están tejidas a mano con hilos de dos colores y sujetas al libro en diferentes puntos con el hilo de la cabezada.

Las guardas originales eran de papel jaspeado. Se han sustituido por otras de papel estampado de color morado. Tiene hojas de respeto.

Los cortes van dorados con pan de oro, bruñidos y cincelados con una greca geométrica en los bordes.

Los cantos están decorados con una rueda de motivos vegetales.

Decoración de las tapas. Enmarcadas por una bordura de tres filetes: dos de hilo fino y la exterior discontinua. Un adorno en forma de jarrón con flores se coloca en las esquinas interiores. Este jarrón es resultado de la combinación de dos hierros: un jarrón y un florón. 
Un octógono trazado con los mismos filetes que la bordura se dispone en el interior. La parte central se decora con un medallón ovalado que reproduce un escudo heráldico en el que se aprecia un capelo. Está ejecutado con una plancha.

12. Breviarium augustinianum ad usum fratrum et monialium ordinis eremitatum $S$. Augustini: officia \& ritus breviarii Romani, nec non suis locis, ex concessione apostolica, ejusdem Ordinis prorpia complectens...: pars autumnalis. Antuerpiae: ex Typographia Plantiniana, 1718.

T. 98280.

17 x 10 x $5 \mathrm{~cm}$.

Encuadernación de piel color oscuro sobre madera con cierres de metal.

El lomo va pegado. Tiene 3 nervios sencillos, resaltados por un filete de puntos discontinuos. Un florón decora el centro de los entrenervios.

Las cabezadas son de un solo capitel; van montadas al aire; están tejidas a mano y sujetas al libro en diferentes puntos con el hilo de la cabezada.

Las guardas son de papel verjurado. Tiene hojas de respeto.

Los cortes están dorados con pan de oro, bruñidos y cincelados.

Decoración de las tapas. El borde presenta un recuadro formado por un filete de puntos discontinuos con florones en los ángulos interiores. El espacio central se decora con una cartela oval que representa un corazón rematado por la cruz y traspasado por dos flechas.

13. Caeremoniale episcoporum Clementis VIII primum, nunc denuo Innocenti papae $X$, auctoritate recognitum... Editio prima in Belgio. Antuerpiae: apud Henricum \& Cornelium Verdussen, 1713.

T. 98297.

$38 \times 26$ × 4,5 cm.

Encuadernación de piel color marrón claro sobre madera. Lleva cierres metálicos.

El lomo va pegado. Presenta 5 nervios resaltados por filetes dorados. Se han dispuesto hierros de florones en los entrenervios.

Las cabezadas son de un solo capitel; van montadas al aire; están tejidas a mano con hilos de dos colores y sujetas al libro en diferentes puntos con el hilo de la cabezada.

Las guardas son de papel verjurado.

Los cortes van dorados con pan de oro, bruñidos y cincelados. Reproducen una orla formada por flores de ocho pétalos metidas en círculos.

Decoración de las tapas. Se trazan dos encuadramientos concéntricos separados por una entrecalle libre de decoración. Los encuadramientos están unidos diagonalmente por las esquinas y por el centro de los lados. Ambos encuadramientos están ejecutados con finas ruedas de motivo vegetal. Las esquinas interiores del encuadramiento central están decoradas con un florón y la mitad de los lados con pequeños hierros de flores. Las esquinas exteriores del encuadramiento más cercano al borde se decoran con los mismos pequeños hierros de flores, al igual que la mitad de sus lados. 
14. Caeremoniale episcoporum Clementis VIII primum, nunc denuo Innocenti papae $X$, auctoritate recognitum... Editio prima in Belgio. Antuerpiae: apud Henricum \& Cornelium Verdussen, 1713.

T. 98013.

$38 \times 26 \times 4,5 \mathrm{~cm}$.

Encuadernación de piel color marrón claro sobre madera. Lleva cierres metálicos.

El lomo va pegado. Está formado por 5 nervios resaltados por paletas de motivos vegetales. Se colocan hierros de florones en los entrenervios.

Las cabezadas son de un solo capitel; van montadas al aire; están tejidas a mano con hilos de dos colores y sujetas al libro en diferentes puntos con el hilo de la cabezada.

Las guardas son de papel verjurado.

Los cortes van dorados con pan de oro, bruñidos y cincelados.

Decoración de las tapas Presentan dos recuadros formados por una fina rueda de motivo vegetal. Los dos recuadros se unen entre sí por tramos de la misma rueda. Las uniones se realizan en el centro de cada lado y en las esquinas. Las terminaciones de estos tramos en la zona exterior del recuadro externo presentan pequeños florones. El espacio central de la tapa se decora con un gran florón (formado por la unión de cuatro). Este florón aparece bordeado de otros hierros menores en dirección de los puntos cardinales, que se sitúan también en el centro de la parte interior de los lados del recuadro interior. En los ángulos se aprecian unos florones de mayor tamaño.

15. Martirologium Romanum Gregorii XIII Pont. Max. Jussu editum, et Clementi PP. auctoritate recognitum accessit huic editioni Eorum memoria, qui à Summis Pontificibus, usque ad Innocentium XIII. Pont. Max. in Sanctorum numerum relati sunt. Antuerpiae: ex Typographia Plantianiana, 1723.

T. 98358.

$21,5 \times 14 \times 3,5 \mathrm{~cm}$.

Encuadernación de piel color oscuro sobre madera. Presenta cierres metálicos.

El lomo va pegado. Está formado por 4 nervios resaltados por un filete. En el centro de los entrenervios se ha plasmado un florón.

Las guardas son de papel verjurado.

Los cortes van dorados con pan de oro y bruñidos.

Decoración de las tapas. Están enmarcadas con una fina rueda de un hilo dorado. Se disponen cuatro florones en las esquinas interiores. Un adorno constituido por cuatro florones unidos por el vértice se sitúa en el centro de la tapa.

16. Martyrologium romanum Gregorii XIII, Urbani VIII et Clementis X auctoritate recognitum necnon a Benedicto XIV auctum \& castigatum... Matriti: ex typograph. D. Antonii de Sancha: a costa de la Real Compañia de Impresores y Libreros del Reyno, 1773.

T. 98348 (1).

$21 \times 14 \times 3,5 \mathrm{~cm}$. 
Encuadernación de piel color oscuro sobre madera con cierres de metal.

El lomo es hueco. Está formado por 3 nervios resaltados por filetes dorados. Los entrenervios incluyen un florón en el centro. La decoración ha perdido el oro.

Las cabezadas son de un solo capitel; van montadas al aire; están tejidas a mano con hilos de dos colores (amarillo y marfil). Están sujetas al libro en diferentes puntos con el hilo de la cabezada.

Las guardas son de papel verjurado. Lleva hojas de respeto.

Los cortes van dorados con pan de oro, bruñidos y cincelados. Reproducen una greca en la que destacan los motivos de estrellas.

Decoración de las tapas. Están enmarcadas con una fina rueda de motivo de cadeneta. Las ruedas se cruzan en las esquinas. En los ángulos interiores se disponen unos florones con forma de girasol. Un óvalo con el motivo iconográfico de las 5 llagas, rodeado de cuatro florones que alternan con otros más pequeños se sitúa en el centro de la tapa.

17. Memorial genealogico, antiguedad, origen, y servicios de la ilustre, y memorable casa de Quiròs, y continuada sucession en ella hasta D. Gabriel Bernardo de Quiròs, Marques de Monreal, Capitan General del Exercito, y Provincia de Estremadura; y su hijo Don Juan Baptista Bernardo de Quiròs, Vizconde de Miralcazar, essempto de la Reales guardias de Corps, y Coronel de los Exercitos de el Rey nuestro Señor. [S.l.: s.n., s.a.].

H. 35081.

$27 \times 19,5 \times 1 \mathrm{~cm}$.

Encuadernación en pasta española de piel de badana color marrón, jaspeada en negro con sulfato de hierro. Se dispone sobre cartón.

El lomo va pegado. Está formado por 4 nervios. Lleva florones en los entrenervios.

Las cabezadas son de un solo capitel; van montadas al aire; están tejidas a mano con hilos de dos colores: hueso y azul. Están sujetas al libro en diferentes puntos con el hilo de la cabezada.

Las guardas son de papel verjurado.

Decoración de las tapas. Presenta una bordura formada por una rueda de un hilo dorado. Las esquinas interiores se adornan con una combinación de dos hierros que reproducen un jarrón con un ramo de flores. Otros hierros florales se apoyan en la mitad central de los lados de la bordura. Cuatro de los anteriores hierros unidos por el vértice y rodeados de otros más pequeños, configurando un adorno circular, se disponen en el centro de la tapa.

18. Oficio de la Semana Santa: segun el Missal y Breviario Romano: que se publicaron por mandado de... Pio V y se reconocieron por... Clemente VIII y Urbano VIII. En Amberes: en la Archiemprenta plantiniana, 1739.

T. 98370 .

$16,5 \times 10 \times 4 \mathrm{~cm}$. 
Encuadernación de piel de color oscuro sobre madera con cierres metálicos.

El lomo va pegado. Está formado por 4 nervios sencillos. De la decoración sólo se aprecian (por el fuerte desgaste) un filete que resalta los nervios y un florón en el centro de los entrenervios.

Las cabezadas son de un solo capitel; van montadas al aire; están tejidas a mano con hilos de dos colores y sujetas al libro en diferentes puntos con el hilo de la cabezada.

Las guardas son de papel verjurado.

Los cortes están dorados con pan de oro, bruñidos y cincelados con un punzón reproduciendo una cenefa formada por grandes margaritas de seis pétalos.

Decoración de las tapas. Están enmarcadas con una fina rueda de un hilo dorado. En las esquinas interiores se disponen cuatro florones. En el centro de la tapa se sitúa un adorno constituido por cuatro florones unidos por el vértice.

19. Pontificale Romanum. Antuerpiae: ex officina Plantiniana Balthasaris Moreti, 1663.

T. 98333.

$35 \times 23 \times 5,5 \mathrm{~cm}$.

Encuadernación en piel de color marrón claro sobre madera con cierres metálicos.

El lomo va pegado. Está formado por 4 nervios, resaltados por paletas de motivo vegetal. En el centro de los entrenervios se sitúa un florón.

Las cabezadas son de un solo capitel; van montadas al aire; están tejidas a mano con hilos de dos colores y sujetas al libro en diferentes puntos con el hilo de la cabezada.

Las guardas son de papel verjurado.

Los cortes van dorados con pan de oro, bruñidos y cincelados con un punzón reproduciendo una orla formada por flores de ocho pétalos metidas en círculos.

Decoración de las tapas. Dos recuadros formados por una fina rueda de motivo vegetal. Los dos recuadros se unen entre sí por tramos de la misma rueda, dispuestos en el centro de cada lado y en las esquinas. Las terminaciones de estos tramos presentan pequeños hierros en forma de florón con motivo de una granada, situados en la zona exterior del recuadro externo. El espacio central de la tapa se decora con un gran florón (formado por la unión de cuatro florones con motivos de granadas) bordeado de otros hierros menores (flores, frutos y pequeños círculos vacíos). Todo ello configura un motivo en forma de cuadrado girado, que se alarga en los extremos superior e inferior por la colocación de sendos hierros de una flor con tallo y hojas. En los ángulos interiores se sitúan florones.

20. Pontificale Romanum Clementis VIII et Urbani PP. VIII auctoritate recognitum, nunc demo a... Benedicto P. XIV editum et auctum. Matriti: ex Typographia D. Joachimi Ibarrae: sumptibus societatis Typographorum Bibliopolarumqve, 1785.

T. 98022.

$38 \times 25 \times 6,5 \mathrm{~cm}$.

Encuadernación de piel color marrón claro sobre madera. 
El lomo va pegado. Está formado por 6 nervios sencillos, resaltados por paletas. En el centro de los entrenervios se dispone un florón.

Las cabezadas son de un solo capitel; van montadas al aire; están tejidas a mano con hilos de dos colores: azul y hueso y sujetas al libro en diferentes puntos con el hilo de la cabezada.

Las guardas son de papel verjurado. Lleva hojas de respeto.

Los cortes están dorados con pan de oro, bruñidos y cincelados con un punzón formando una ornamentación de un adorno festoneado en los bordes.

Decoración de las tapas. Están enmarcadas por dos recuadros formados por finas ruedas con motivo de cinta liada. Los dos recuadros están unidos desde las esquinas por segmentos de la misma rueda. En los ángulos del recuadro interior se han colocado florones. El centro de la tapa está decorado por cuatro florones del mismo tipo agrupados en losange.

21. Recopilación de las leyes destos Reynos, hecha por mandado de... Philippe Segundo...: contienense en este libro las leyes hechas hasta fin del año de mil y quinientos y ochenta y uno, excepto las leyes de Partida y del Fuero y del Estilo... Acabose de imprimir esta presente impression en Alcala de Henares: en casa de Iuan Iñiguez de Liquerica [sic]..., 1581.

D. 1084.

Obra en 2 volúmenes.

$33 \times 23$ × $6 \mathrm{~cm}$.

Encuadernación de piel color oscuro sobre cartón.

El lomo va pegado. Está formado por 5 nervios dobles resaltados por un triple filete. Un florón decora el centro de los entrenervios.

Los cortes van dorados con pan de oro, bruñidos y cincelados.

Decoración de las tapas. Se inicia con un rectángulo formado por dos hilos finos. En el interior de manera concéntrica se dispone otro rectángulo semejante separado por una calle. Las esquinas exteriores e interiores van decoradas con florones. La zona central de la tapa presenta un gran rombo formado por lados de dobles hilos. Cuatro florones unidos por los vértices se cobijan en el interior del rombo. El exterior del rombo se decora con hierros de motivo curvo y pequeñas volutas que componen un marco de gran elegancia.

22. Rituale Romanum Pauli V Pont Maximi iussu editum; ac deinde a Benedicto XIV auctum; cum cantu toletano \& appendice ex Manuali Toletano. Matriti: ex tipogrphia Benedicti Cano: sumptibus societ. Reg. Typographorum bibliopolarumque regni, 1787.

T. 98344.

$24 \times 18 \times 4,5 \mathrm{~cm}$.

Encuadernación de piel color oscuro sobre madera con vestigios de llevar broches.

El lomo va pegado. Está formado por 4 nervios resaltados por una paleta con motivo de cinta liada. Los entrenervios disponen en el centro de un hierro en forma de granada con hojas. 
Las cabezadas son de un solo capitel; van montadas al aire; están tejidas a mano con hilos de dos colores: azul y hueso. Están sujetas al libro en diferentes puntos con el hilo de la cabezada.

Las guardas son de papel verjurado.

Los cortes van dorados con pan de oro, bruñidos y cincelados.

Decoración de las tapas. Está constituida por un encuadramiento formado por una rueda con motivo de cinta liada. Unos pequeños hierros florales aparecen en las esquinas exteriores y unos florones en las esquinas interiores. Un adorno formado por la repetición de cuatro florones del mismo tipo que los anteriores y unidos por el vértice se coloca en el centro de la tapa.

\subsection{Encuadernaciones decoradas con filetes gofrados a los que acompañan florones dorados}

23. Breviarium Romanum a Paulo Tertio recens promulgatum, ex sacra potissunum scriptura [et] probatis sanctorum historiis constans ab authore denuo recognitumque [et] antiphois, homeliis, precibus, sanctorum $c^{-}$omemo rationibus, [et] aliis id genus additam $^{-}$etis multifari ${ }^{-}$locupletat ${ }^{-}$uque ut in prefatione lucul ${ }^{-}$etius explicatur. Parissiis: a Ioanne Paruo... et ab Yolanda Bonh ${ }^{-}$ome..., 1539 (excudebat... Oliverius Mallard...).

E.N. 207.

10 × 8,5 × $4 \mathrm{~cm}$.

Encuadernación en piel marrón oscuro sobre cartón.

El lomo va pegado. Está formado por 5 nervios dobles.

Los cortes van dorados con pan de oro, bruñidos y cincelados reproduciendo una cenefa con flores.

Decoración de las tapas. Bordura gofrada formada por un filete de un hilo fino. En el centro llevan sobrepuesta una pieza rectangular decorada en oro, unida diagonalmente a la bordura por las esquinas con cuatro filetes de un hilo. En la pieza se identifica el águila bicéfala rodeada de una fina cenefa circular de ornamentación vegetal y cuatro angelotes en las esquinas; a continuación una inscripción en latín de la que se identifican las palabras: "VERBUM - DOMINI - [...] - ETERNUM...". La inscripción va dispuesta dentro de un marco formado por un filete de dos hilos. La composición se cierra con dos cordones en los lados mayores y dos cenefas diferentes de decoración vegetal en la zona superior e inferior.

24. Emotte, Pierre. Catholica fidei professio primum vtriusque testamenti deinde Sanctissimorum Patrum... testimoniis confirmata: digesta in quatuor libros... Parisiis: apud Michaëlem Sonnium..., 1578.

T. 86060.

$17 \times 12 \times 5 \mathrm{~cm}$

Encuadernación de piel color marrón sobre cartón.

El lomo va pegado. Está formado por 4 nervios sencillos. 
Las cabezadas son de un solo capitel; van montadas al aire; están tejidas a mano con hilos de dos colores (azul y marfil) y sujetas al libro en diferentes puntos con el hilo de la cabezada.

Las guardas son de papel verjurado.

Los cortes van coloreados con tinta verde.

Decoración de las tapas. Se inicia con un encuadramiento formado por tres filetes de hilo fino que se repiten en otro encuadramiento más pequeño, concéntrico e interior. Ambos encuadramientos están separados por una entrecalle sin decoración. Las esquinas del encuadramiento interior están rematadas con hierros dorados en forma de ramito con tres hojas. Un florón aldino estampado en oro aparece en el centro de la tapa.

\subsection{Encuadernaciones decoradas con filetes gofrados y dorados y florones gofrados y dorados}

25. Pontificale Romanum. Nunc primum typis Plantianianis emendatius recusum. Antuerpiae: ex officina Plantiniana: apud Balthasarem Moretum et viduam Ioannis Moreti et Io. Meursium, 1627.

T. 98334.

$36 \times 24 \times 6 \mathrm{~cm}$.

Encuadernación de piel color marrón sobre cartón con cierres de cintas de seda.

El lomo va pegado. Está formado por 5 nervios dobles decorados en dorado con una paleta (que casi no se percibe) y resaltados por un filete. En el centro de los entrenervios se ha colocado un hierro en forma de flor de cinco pétalos con tallo y hojas.

Las cabezadas son de un solo capitel; van montadas al aire; están tejidas a mano con hilos de dos colores y sujetas al libro en diferentes puntos con el hilo de la cabezada.

Las guardas son de papel verjurado. Lleva hojas de respeto. Incluye varias cintas separadoras de seda de diferentes colores.

Los cortes están dorados con pan de oro y cincelados con un punzón reproduciendo varias líneas punteadas sobre las que descansan arcos punteados a modo de festón.

Decoración de las tapas. Destacan dos encuadramientos compuestos por una original combinación de filetes. Están separados por una calle. El encuadramiento más cercano al borde se forma por dos filetes dorados delimitados a ambos lados por un juego de triple filete gofrado (más ancho el central). El espacio entre los dos filetes dorados va decorado en la zona de las esquinas con ruedas de decoración vegetal formando esquineras. La composición de filetes del recuadro interior es semejante, pero incorpora un filete dorado más, que se interrumpe cerca de las esquinas para incorporar unos adornos curvos formados por la unión de varios hierros (uno en forma de flor en el centro y dos a los lados, azurados, con hojas curvas). Las esquinas exteriores de este encuadramiento se adornan con florones dorados. Un óvalo realizado en dorado mediante una plancha que representa la escena de la Anunciación se sitúa en el espacio central.

\subsection{Encuadernaciones decoradas con grecas de elementos vegetales}

26. Ariosto, Ludovico. Orlando Furioso. In Lione: appresso Bastiano di Bartholomeo Honorati, 1556 (per Iacopo Fabro). 
E.N. 201

$25 \times 17,5 \times 4 \mathrm{~cm}$.

Encuadernación de piel color marrón claro sobre cartón. Técnica del gofrado.

El lomo va pegado. Está formado por 4 nervios dobles.

Las guardas son de papel verjurado.

El corte delantero lleva letras del título escritas con tinta ferruginosa.

Decoración de las tapas: se estructura en dos bandas u orlas rectangulares concéntricas dejando entrecalles libres. Las orlas están encuadradas con tres filetes, el central más grueso. Las entrecalles están libres de decoración, excepto en las esquinas donde se entrecruzan los filetes que rodean las orlas formando pequeños cuadrados. Las orlas van decoradas con motivos vegetales. El rectángulo central lleva cuatro florones en las esquinas. Un óvalo con las iniciales "IHS”, la cruz y tres clavos (responde al monograma de la Compañía de Jesús) se ha situado en el centro y unos hierros que reproducen la figura del “Agnus Dei” (o Cordero místico) por encima y debajo del óvalo.

27. Cipriano, Santo. D. Caecilii Cypriani Episcopi Carthaginiensis et martyris Opera. Lugduni: apud Seb. Gryphium, 1550.

T. 29105

$17 \times 12 \times 5 \mathrm{~cm}$

Encuadernación de piel color oscuro sobre cartón con vestigios de llevar cierres metálicos. Técnica del gofrado.

El lomo va pegado. Está formado por 4 nervios dobles decorados con un filete y resaltados por triples filetes (más ancho el central).

Las cabezadas son de un solo capitel; van montadas al aire; están tejidas a mano y sujetas al libro en diferentes puntos con el hilo de la cabezada.

Las guardas son de papel verjurado.

Decoración de las tapas: enmarcadas por dos bandas u orlas concéntricas sin que exista entrecalle. Están ejecutadas con ruedas. La primera orla (cercana al borde) es de motivo vegetal simétrico de tipo renacentista. La segunda orla es de diseño asimétrico con motivos de hojarasca, rizos y roleos. Las dos orlas están separadas y delimitadas por dobles filetes finos. Un hierro en forma de caballo y otros hierros con motivos de jarrones, por encima y por debajo de éste, se disponen en el eje central de la tapa. Unos florones se sitúan en los ángulos interiores.

28. Juan Crisóstomo, Santo. Divi Ioannis Chrysostomi... divinorum operum tomus primus et vltimus: qui ob multiplicem ac miscellaneam varietatem argumentorum quae complectitur... Venetiis: [s.n.], 1574.

T. 29050 (I).

Obra en 4 tomos.

23 x 17 × $7 \mathrm{~cm}$. (Tomo I), 23 x 17 x $6 \mathrm{~cm}$. (Tomo II y Tomo V), 23 x 17 x $4 \mathrm{~cm}$. (Tomo III), $23 \times 17 \times 8,5 \mathrm{~cm}$. (Tomo IV). 
Encuadernación de piel color marrón claro sobre madera con vestigios de llevar cierres de metal.

El lomo va pegado. Está formado por 4 nervios dobles decorados con un filete y resaltados por triple filete (más grueso el central) que se adentran en las tapas.

Las cabezadas son de un solo capitel; van montadas al aire; están tejidas a mano y sujetas al libro en diferentes puntos con el hilo de la cabezada.

Las guardas son de de papel verjurado.

El corte delantero tiene letras del nombre del autor abreviado realizadas con tinta ferruginosa.

Decoración de las tapas. Se inicia con una banda u orla exterior formada por animales, flores y hojas. A continuación y separada de esa orla por una calle se dispone otra orla rectangular y concéntrica formada por medallones circulares con tres tipos diferentes de caras en posición de perfil. Los medallones van unidos por decoración vegetal. Las orlas están delimitadas por triple filete, más grueso el central. Estos filetes se cruzan en las esquinas dando lugar a rectángulos.

Cuatro florones se han colocado en las esquinas del rectángulo central. Otros cuatro florones de este mismo tipo unidos por el vértice aparecen en el centro de la tapa; a los que se añaden dos florones más, uno por encima y otro por debajo, alargando la composición.

29. Manuale processionum: cum benedictionibus solemnibus, privatisque omnibus, quibus utitur Sancta Romana Ecclesia, [et] precibus, aliisque quamplurimis, omnibus officium romanum periolvenribus inserviens. Ulyssipone Orientali: ex Typographia Augustiniana, 1733.

T. 98248.

$21,5 \times 16 \times 4 \mathrm{~cm}$.

Encuadernación de piel color oscuro sobre cartón. Técnica del gofrado y técnica del dorado.

El lomo va pegado. Está formado por 4 nervios sencillos resaltados por cuatro filetes. Un tejuelo con letras del título en dorado se sitúa en el segundo entrenervio; va enmarcado por doble filete, uno liso y otro festoneado.

Las guardas son de papel verjurado.

Los cortes van coloreados con gotas de tinta roja.

Decoración de las tapas. Van enmarcadas por una rueda vegetal con motivo de girasoles, delimitada con cinco filetes de hilo fino. El espacio central se decora con un aspa grande de cinco filetes de hilo fino.

30. Rodrigues, Manuel. Summa de casos de consciencia con aduertencias muy prouechosas para confessores: con vn Orden Iudicial a la postre, en la qual se resuelue lo mas ordinario de todas las materias morales: añadida agora de nueuo... y corregida por el mismo author... En Salamanca: en casa de Andres Renaut, 1600.

T. 70228.

$20 \times 6 \times 6,5 \mathrm{~cm}$. 
Encuadernación de piel color marrón claro sobre cartón. Técnica del gofrado y técnica del dorado.

El lomo va pegado. Está formado por 4 nervios dobles decorados y resaltados por triple filete, más ancho el central, que se prolonga en las tapas en forma de triángulo. Tres hierros en forma de flor con pétalos se disponen en los entrenervios.

Las cabezadas son de un solo capitel; van montadas al aire; están tejidas a mano y sujetas al libro en diferentes puntos con el hilo de la cabezada.

Las guardas son de papel verjurado con numerosas anotaciones manuscritas.

Decoración de las tapas. Se inicia con una bordura de tres filetes, más grueso el central. Se completa con dos bandas u orlas que forman recuadros concéntricos separados por calles. Las orlas están delimitadas por tres filetes, más grueso el central, que se cruzan en las esquinas de las calles formando espacios geométricos en forma de cuadrados que se decoran en dorado con un hierro en forma de roseta. Las orlas están realizadas con ruedas estampadas en seco con guirnaldas de flores y hojas. El espacio central se rellena con hierros sueltos dorados: el central tiene forma de león rampante con otro hierro sobrepuesto en forma de cruz; dos hierros de rosetas por encima y por debajo y en las esquinas interiores hierros en forma de corazón.

31. Stapleton, Thomas. Promptuarium morale super euangelia dominicalia totius anni. Lugduni: sumptibus Ioannis Baptistae Buysson, 1596.

T. 70177.

$18 \times 13 \times 4 \mathrm{~cm}$.

Encuadernación de piel color marrón claro sobre cartón. Técnica del gofrado y técnica del dorado.

El lomo va pegado. Está formado por 3 nervios dobles decorados encima con un filete gofrado y resaltados por tres filetes que se prolongan hasta las tapas en forma triangular. Un hierro dorado en forma de león rampante coronado se aprecia en los entrenervios.

Las cabezadas son de un solo capitel; van montadas al aire; están tejidas a mano y sujetas al libro en diferentes puntos con el hilo de la cabezada.

Las guardas son de papel verjurado.

El corte delantero lleva letras del nombre del autor escritas con tinta ferruginosa.

Decoración de las tapas. Comienza con una bordura gofrada formada por tiple filete, más ancho el del centro. Le sigue una gruesa banda u orla de forma rectangular estampada en seco, originada por la repetición paralela de una rueda compuesta por un motivo de pequeñas flores de cuatro pétalos unidas por cintas onduladas. Las flores se alternan según dos tipos, unas con los pétalos rellenos y otras con los pétalos vacíos. La orla va separada de la bordura por una entrecalle y está delimitada por tres filetes gofrados, más grueso el del centro, que se cruzan en las esquinas de la entrecalle formando pequeños rectángulos. El espacio interior de la tapa se rellena con hierros sueltos en dorado: en la mitad del eje central un águila y por encima y por debajo, hierros de leones rampantes coronados. Finalmente se aprecian cuatro florones en las esquinas interiores. 
32. Garibay y Zamalloa, Esteban. Los XL libros d'el compendio historial de las chronicas y vniuersal historia de todos los reynos de España. Impresso en Anueres: por Christophoro Plantino...: a costa d'el autor, 1571.

E.N. 209.

$34 \times 24 \times 4 \mathrm{~cm}$.

Encuadernación de piel color marrón claro sobre madera con marcas de llevar broches. Técnica del gofrado y técnica del dorado.

El lomo va pegado. Está formado por 5 nervios dobles resaltados por triple filete gofrado, más ancho el central. Los filetes se prolongan hasta las tapas en forma triangular.

Las cabezadas son de un solo capitel; van montadas al aire; están tejidas a mano y sujetas al libro en diferentes puntos con el hilo de la cabezada.

Los cortes van coloreados con tinta roja.

Los cantos están gofrados.

Decoración de las tapas. Se componen de dos orlas separadas por una entrecalle decorada con florones dorados en las esquinas y en el centro de los lados mayores. Las orlas están realizadas con ruedas estampadas en seco con motivo de medallones ovalados de cabezas de perfil unidos por motivos vegetales. Las orlas van delimitadas por triples filetes, más grueso el del centro. El rectángulo central se divide en tres partes (mayor la central) por triples filetes del mismo tipo. La parte del centro se decora con un rombo formado por una rueda de motivos vegetales delimitada por los triples filetes. La parte interior del rombo está adornada con un gran florón dorado formado por la unión de cuatro más pequeños y las esquinas por cuatro florones. Las otras dos partes presentan una misma decoración: están divididas en tres espacios triangulares por los triples filetes, cada espacio se decora con un florón dorado. Se utiliza la técnica del dorado para los florones y la del gofrado para el resto.

33. Graduale Romanun ... S. Pii V ... iussu editi ... Venetiis: Ex Typographia Balleoniana, 1760.

E.N. 225.

$50 \times 35 \times 8 \mathrm{~cm}$.

Encuadernación de piel color oscuro sobre cartón. Lleva esquineras de metal y vestigios de haber tenido cierres y cabujones de metal. Técnica del gofrado.

El lomo pegado está formado por 6 nervios dobles.

Las cabezadas son de un solo capitel; van montadas al aire; están tejidas a mano con hilos de dos colores y sujetas al libro en diferentes puntos con el hilo de la cabezada.

Las guardas son de un papel estampado moderno. Se conservan sólo en parte.

Los cortes van coloreados con tinta roja.

Decoración de las tapas. Se inicia con una bordura de dos finas ruedas, una con motivos geométricos y otra vegetal. A continuación se disponen dos bandas u orlas formadas por ruedas de flores separadas por una calle decorada con una rueda de pequeños óvalos con una flor en el interior. Un encuadramiento delimita el espacio central formado por las mismas ruedas que la bordura. Presenta en el interior un rombo dividido 
en cuatro y trazado con las citadas ruedas. Las esquinas interiores se adornan con hierros formando un adorno en cuarto de esfera.

34. Sisto da Siena. Bibliotheca Sancta ... Venetiis: apud Franciscum Franciscium Senensem, 1575.

T. 26371.

$23 \times 16 \times 8 \mathrm{~cm}$.

Encuadernación de piel color marrón claro sobre madera con vestigios de llevar broches. Técnica del gofrado.

El lomo pegado está formado por 4 nervios dobles decorados y resaltados por triple filete (más ancho el central) que se prolonga en las tapas. Los entrenervios van ornamentados con un florón en el centro y otros más pequeños en los ángulos.

Las cabezadas son de un solo capitel; van montadas al aire; están tejidas a mano y sujetas al libro en diferentes puntos con el hilo de la cabezada.

El corte delantero lleva letras del título escritas con tinta ferruginosa.

Decoración de las tapas. Está constituida por dos bandas u orlas que forman rectángulos concéntricos separados por una calle vacía de decoración. Las orlas enmarcan un rombo central y van unidas en las esquinas por tres filetes, más grueso el del centro y están delimitadas por tres filetes del mismo tipo. Las orlas están realizadas mediante ruedas de motivos vegetales con dos diseños diferentes: la exterior presenta como motivo destacado pequeñas flores de cuatro pétalos unidas por una especie de cinta ondulada; la interior lleva una decoración más menuda, destacando unas flores con pétalos muy finos que semejan soles. El espacio central se decora con un rombo grande trazado con el mismo tipo de rueda que el de la orla interior. El monograma de Cristo acompañado con la cruz y los 3 clavos, rodeado de cuatro pequeños florones en la dirección de los puntos cardinales, se coloca en el centro del rombo a modo de superlibris. Estos florones se repiten en los ángulos superior e inferior del rombo y otros de mayor tamaño en los ángulos interiores del espacio central.

\subsection{Encuadernaciones decoradas con grecas de cabecitas encerradas en óvalos o en círculos}

35. Commentaria in psalmos dauidicos prisci cuiusdam auctoris incogniti in duos divisa tomos...: additi sunt duo indices... Post complutensen editionen recognita... Lugduni: apud Carolum Pesnot, 1582.

T. 22000.

Obra en 2 tomos.

$36 \times 24 \times 6 \mathrm{~cm}$.

Encuadernación de piel color marrón claro sobre madera con vestigios de llevar cierres de metal. Técnica del gofrado.

El lomo pegado está formado por 5 nervios dobles decorados y resaltados por triple filete (más acho el del centro) que se prolongan en las tapas. Los entrenervios se adornan 
en el centro con un hierro que reproduce el Cordero místico y con hierros de florones a ambos lados.

Decoración de las tapas. Tres bandas con dos entrecalles libres que encuadran un rectángulo central. Las tres bandas u orlas están realizadas con la misma rueda de medallones en los que aparecen hombres con casco de perfil según tres modelos diferentes. El resto de la orla está decorada con motivos vegetales. Las orlas están encuadradas con tres filetes, el central más grueso. Las entrecalles están libres de decoración, excepto en las esquinas donde se entrecruzan los filetes que rodean las orlas formando pequeños cuadrados. El rectángulo central lleva en las esquinas cuatro florones con un corazón; en el centro otros florones de mayor tamaño van unidos por su vértice formando un adorno rectangular. Dos cartelas ovaladas con las iniciales "JHS", la cruz y los clavos se aprecian en el eje vertical. Las cartelas llevan en su perímetro cuatro hierros con corazones semejantes a los de las esquinas.

36. Estienne, Robert. Thesauri linguae latinae tomus III. Lugduni: [s.n.], 1573.

L. 908 (III).

Obra en 4 tomos.

$40,5 \times 25,5 \times 7,5 \mathrm{~cm}$.

Encuadernación de piel color marrón sobre madera con vestigios de llevar broches. Técnica del gofrado.

El lomo pegado está formado por 5 nervios dobles decorados con un filete y resaltados por tres filetes que se prolongan en las tapas formando triángulos. Los entrenervios se decoran en el centro con un hierro en forma de delfín coronado, con el extremo de la cola dividida en dos y otros hierros en forma de corazón a cada lado.

Las cabezadas de un solo capitel van montadas al aire; están tejidas a mano y sujetas al libro en diferentes puntos con el hilo de la cabezada.

Las guardas son de papel verjurado.

El corte delantero lleva escritas con tinta ferruginosa las letras (del abecedario) a las que se refiere el contenido de cada tomo.

Decoración de las tapas. Se inicia con una bordura exterior formada por tres hilos lisos, más ancho el central. A continuación se disponen tres orlas concéntricas realizadas con ruedas separadas por entrecalles vacías y bordeadas por tres filetes (más ancho el central) que dan lugar a espacios geométricos cuadrados libres de decoración. Las ruedas presentan la misma decoración de medallones (unos circulares y otros ovalados) con tres perfiles de hombres diferentes que se van alternando (uno con corona, otro con casco y el tercero sin cubrir) y decoración vegetal entre los medallones. El rectángulo central lleva cuatro florones en las esquinas; un escudo heráldico en el centro formado por un león y un capelo, ornamentado alrededor por pequeños hierros de corazones y de flor de lis; y dos medallones ovalados colocados por encima y por debajo, el primero con el monograma de Cristo, la cruz y los clavos, y el segundo con el de la Virgen María acompañado de una corona. 
37. Gregorio I, Papa, Santo. Beati Gregorii Papae Operum tomus secundus: complectens aliquot Sacrae Scripturae expositiones, tum homilias super Ezechielem et in Euangelia, tum eiusdem Epistolas... Venetiis: apud Bartholomaeum Rotam, 1571.

T. 29123.

$22 \times 16 \times 8 \mathrm{~cm}$.

Encuadernación de piel marrón claro sobre madera con vestigios de llevar broches, cantoneras y cabujones. Técnica del gofrado.

El lomo pegado está formado por 4 nervios sencillos decorados y resaltados por triple filete, más ancho el central, que se prolongan en las tapas en forma de triángulo. Un hierro con la figura de un sol de rasgos humanos se ha colocado en el centro de los entrenervios. En la zona de pie el espacio es más ancho y se divide en dos por un juego de triple filete: en el primer espacio se repite el hierro del sol y en el otro se traza una retícula.

Las cabezadas de un solo capitel van montadas al aire; están tejidas a mano y sujetas al libro en diferentes puntos con el hilo de la cabezada.

Las guardas son de papel verjurado.

El corte delantero lleva una inscripción escrita con tinta ferruginosa.

Decoración de las tapas. Dos bandas u orlas forman rectángulos concéntricos. Están separadas por una entrecalle vacía de decoración. Las orlas están delimitadas por triple filete, más grueso el del centro y unidas diagonalmente en las esquinas por filetes del mismo tipo. Las orlas están realizadas con ruedas del mismo diseño: dos modelos de medallones ovalados con cabezas de perfil separados por decoración de flores enlazadas por tallos curvos. El espacio interior se decora con el hierro en forma de sol en el centro y dos florones por encima y por debajo, que se repiten en las cuatro esquinas interiores.

38. Nacchianti, Jacobo. Iacobi Naclanti... Operum tomus primus id est Enarrationes in D. Pauli epistolas ad ephesios \& romanos... Sacrae Scriptura medulla... Tractatus item decem et octo... Venetiis: apud Iuntas, 1567 (in officina Lucae Antonij Iuntae).

T. 24100 (1) (I).

$32 \times 22 \times 7 \mathrm{~cm}$

Encuadernación de piel color marrón claro sobre madera. Técnica del gofrado.

El lomo pegado está formado por 4 nervios dobles decorados con filetes (el desgaste impide apreciar los motivos) que se prolongan en las tapas.

Las cabezadas de un solo capitel van montadas al aire; están tejidas a mano con hilos de dos colores y sujetas al libro en diferentes puntos con el hilo de la cabezada.

Las guardas son de papel verjurado.

Decoración de las tapas. Los restos que se conservan permiten intuir que están decoradas por dos bandas u orlas rectangulares concéntricas, decoradas con medallones de dos motivos diferentes que se van alternando: una flor circular de seis pétalos y una calavera. Las orlas están delimitadas por tres filetes, más grueso el central y están separadas por calles vacías de decoración, salvo en las esquinas donde los filetes se cruzan formando cuadrados. Del rectángulo central sólo se aprecia que lleva florones en las esquinas interiores. 
39. Paiva de Andrade, Diogo de. Defensio Tridentinae fidei catholicae et integerrimae quinque libris compraehensa: aduersus haereticorum detestabiles calumnias \& praesertim... Martini Kemnicij Germani. Olysippone: per Antonium Riberium..., 1578.

E.N. 223.

$20,5 \times 15 \times 4,5 \mathrm{~cm}$.

Encuadernación de piel de color marrón claro sobre cartón. Técnica del gofrado y técnica del dorado.

El lomo pegado está formado por 4 nervios dobles. Los entrenervios están decorados en el centro con un hierro de flor. Lleva paletas en la zonas de cabeza y pie y un tejuelo de piel en el segundo entrenervio con estas palabras en letras doradas: PAIVA / DEFENSIO / TRIDENTINAE.

Las cabezadas de un solo capitel van montadas al aire; están tejidas a mano con hilos de dos colores (hueso y verde) y sujetas al libro en diferentes puntos con el hilo de la cabezada.

Las guardas son de papel verjurado.

Los cortes van coloreados con tinta roja.

Decoración de las tapas. Se inicia con una bordura de tres filetes, más grueso el central. Se completa con dos bandas u orlas que forman recuadros concéntricos separados por calles. Las orlas están delimitadas por tres filetes, más grueso el central que se cruzan en las esquinas de las calles formando espacios geométricos en forma de cuadrados decorados en dorado con un hierro en forma de roseta. Las orlas están realizadas con ruedas estampadas en seco de medallones ovalados de cabezas de perfil, unas con corona y otras con casco; van enlazadas por guirnaldas de flores y hojas. El espacio central se rellena con hierros sueltos dorados: en medio un elefante con un castillo en el lomo, por encima y por debajo, un hierro en forma de rosetas y en las esquinas interiores hierros con motivo de rama tres bellotas.

40. Soto, Domingo de. Commentariorum fratris Dominici Soto segobiensis theologi ordinis Praedicatorum... in quartum sententiarum tomus primus. Salmanticae: excudebat Ioannes à Canoua, 1557 (1558).

T. 46056.

$30 \times 21 \times 7 \mathrm{~cm}$.

Encuadernación de piel color oscuro sobre cartón con vestigios de llevar cierres de tiras de piel. Técnica del gofrado.

El lomo pegado está formado por 4 nervios dobles resaltados por tres filetes.

Las cabezadas de un solo capitel van montadas al aire; están tejidas a mano y sujetas al libro en diferentes puntos con el hilo de la cabezada.

Las guardas son de papel verjurado, conservadas parcialmente.

Decoración de las tapas. Se inicia con una bordura de triple filete en los lados mayores. A continuación, separado por una calle, un rectángulo formado por una rueda de óvalos (es lo único que se intuye por el acentuado desgaste) delimitada por triple filete. Le 
siguen otra calle y otro rectángulo con el mismo esquema. En ambas composiciones los filetes del borde exterior se prolongan y se cruzan en las esquinas, dando lugar a espacios geométricos cuadrados libres de decoración. El espacio central se adorna en los ángulos interiores con hierros sueltos en forma de concha y otros dos iguales en el centro.

41. Soto, Domingo de. Fratris Dominici Soto Segobiensis Theologi ordinis Praedicatorum... De Iustitia \& Iure libri decem nunc primùm ab ipso authore... emendati atque multò auctiores redditi... Salmanticae: apud Ioannem Moreno bibliopolam, 1559 (in officina Ioannis Mariae à Terranoua...).

T. 46049.

$30 \times 21 \times 7 \mathrm{~cm}$.

Encuadernación de piel color marrón sobre madera. Técnica del gofrado.

El lomo pegado está formado por 5 nervios dobles decorados con un filete y resaltados por triple filete que se prolonga hasta las tapas en forma triangular. Los entrenervios van decorados con una trama de filetes formando rombos.

Las cabezadas de un solo capitel van montadas al aire; están tejidas a mano y sujetas al libro en diferentes puntos con el hilo de la cabezada.

Las guardas son de papel verjurado.

El corte delantero lleva letras del título escritas con tinta ferruginosa.

Decoración de las tapas. Tres orlas formadas por ruedas y separadas por entrecalles. Las ruedas son de medallones circulares de tres tipos: unos con la cabeza de un angelote de frente; otros con la cabeza de un individuo con casco y otros con una cara de perfil. Los medallones van unidos por motivos vegetales. Las ruedas se presentan delimitadas por triples filetes, más grueso el del centro, que se prolongan y cruzan en las esquinas de las entrecalles formando rectángulos. El espacio central de la tapa se rellena con hierros sueltos: en la mitad un medallón con cabeza de perfil bordeado de un marco festoneado; animales corriendo, por encima y por debajo del medallón. En las esquinas interiores se disponen cuatro florones.

42. Tomás de Aquino, Santo. D. Thomae Aquinatis Additiones ad tertiam eius partem...: ex eiusdem scriptis potissimum collectae... Nunc primum in Hispaniis... excusae typis, quibus accessere aliarum Summae S. Thomae partium Concordantiae... Salmanticae: excudebat Andreas à Portonariis, 1553.

T. 43015.

$31 \times 21 \times 4 \mathrm{~cm}$.

Encuadernación de piel color marrón claro sobre madera con vestigios de llevar broches. Técnica del gofrado.

El lomo va pegado. Está formado por 5 nervios dobles decorados encima y resaltados por triple filete, que se prologa en las tapas en forma de triángulos. En el centro de los entrenervios se dispone un hierro circular y a los lados otros con forma de corazón.

Las cabezadas de un solo capitel van montadas al aire; están tejidas a mano y sujetas al libro en diferentes puntos con el hilo de la cabezada. 
Las guardas son de papel verjurado. Incluye hojas de respeto.

El corte delantero lleva una inscripción escrita con tinta ferruginosa.

Decoración de las tapas. Bordura de triple filete (más grueso el central) y sucesión de tres bandas u orlas que forman recuadros concéntricos separados por entrecalles vacías. Las orlas están delimitadas por tres filetes (más grueso el del centro) que se prolongan y cruzan dando lugar en las esquinas de las calles a espacios geométricos rectangulares sin decorar. Las ruedas están constituidas por medallones circulares con caras de perfil (se alternan 3 modelos distintos) unidos por motivos vegetales. El espacio central se rellena en el centro con un medallón de una cara de perfil; en el eje central se colocan, por encima y por debajo del medallón, unos hierros de animales cuadrúpedos; además, unos pequeños hierros en forma de corazón y de rosetas aparecen repartidos por el resto del espacio. En las esquinas del rectángulo central hay cuatro florones.

43. Tomás de Aquino, Santo. Operum Sancti Thomae Aquinatis, Angelici Doctoris, Divi Thomae Aquinatis summae theologie ... Lugduni: apud Hugonem et Haeredes Aemonis à Porta, 1547.

T. 43048.

Obra en 2 tomos.

$34 \times 22 \times 6 \mathrm{~cm}$.

Encuadernación de piel color marrón claro sobre madera con vestigios de llevar broches. Técnica del gofrado.

El lomo pegado está formado por 5 nervios dobles con decoración que apenas se aprecia. Se intuyen unos triples filetes (más ancho el central) que resaltan los nervios prolongados hasta las tapas en forma triangular. Un hierro del que no se identifica el motivo se adivina en el centro de los entrenervios.

Las cabezadas de un solo capitel van montadas al aire; están tejidas a mano y sujetas al libro en diferentes puntos con el hilo de la cabezada.

Las guardas son de papel verjurado.

El corte delantero tiene una inscripción escrita con tinta y dos corazones.

Decoración de las tapas. Cada tomo presenta un diseño distinto.

Modelo 1: bordura de triple filete (más grueso el central) y sucesión de tres orlas formadas por ruedas separadas por entrecalles. Las ruedas están constituidas por medallones circulares con cabezas de perfil (hay dos tipos) unidos por adornos vegetales. Las ruedas van delimitadas por tres filetes, más grueso el central que se prolongan en las entrecalles dando lugar en las esquinas a espacios geométricos rectangulares sin decorar. El rectángulo central está decorado con tres medallones con caras: uno en el centro y los otros dos en la parte superior e inferior. Entre los medallones y sobre ellos aparecen delfines que intentan imitar a un monstruo.

Modelo 2: bordura de triple filete (más grueso el central) y sucesión de tres orlas formadas por ruedas separadas por entrecalles. Las ruedas están constituidas por medallones ovalados con cabezas de perfil, unidos por motivos vegetales. Las ruedas van delimitadas por tres filetes, más grueso el central, que se prolongan en las entrecalles dando lugar en las esquinas a espacios geométricos rectangulares sin decorar. El espacio 
central de la tapa se rellena con hierros sueltos: en el centro un medallón con cabeza de perfil rodeado de forma alterna por hierros de corazón y florones, que componen un adorno de mayor tamaño; por encima y por debajo, en el eje central se sitúan dos hierros en forma de rama con bellotas; además, se reparten pequeñas rosetas. Finalmente, en las esquinas interiores se colocan cuatro florones.

44. Verrati, Giovanni Maria. Homeliae siue Commentaria in omnia quae ab Adventu Domini vsque ad Dominicam Resurrectionis legi solent Euangelia... Venetiis: apud Ioann. Antonium Bertanum, 1573.

T. 95639.

16 x 11 x 4,5 cm.

Encuadernación de piel color marrón claro sobre madera con vestigios de llevar broches. Técnica del gofrado.

El lomo pegado está formado por 4 nervios dobles decorados encima por un filete y resaltados por tres filetes que se prolongan en las tapas.

Las guardas son de papel verjurado, incompletas y con anotaciones manuscritas.

El corte delantero lleva una inscripción con tinta ferruginosa.

Decoración de las tapas. Dos bandas concéntricas sin calle que las separe enmarcan el espacio central. Las orlas están delimitadas por tres filetes, más grueso el del centro y están ejecutadas con ruedas de medallones de cabezas con casco en posición de perfil (unos circulares y otros ovalados dispuestos de forma alterna). Los medallones van unidos por decoración vegetal plateresca. El espacio central se decora con hierros sueltos: un león en el centro, unos delfines por encima y por debajo, cuatro florones en las esquinas interiores.

\subsection{Encuadernación decorada con grecas de animales en movimiento o reposo entre elementos vegetales}

45. Hebraicorum Bibliorum Veteris Testamenti Latina interpretatio. Antuerpiae: Christophorus Plantinus... excudebat, [1571 ?].

E.N. 226.

Obra en 6 tomos.

$43 \times 29 \times 8,5 \mathrm{~cm}$.

Encuadernación de piel color marrón sobre madera. Técnica del gofrado.

El lomo pegado está formado por 6 nervios dobles decorados y resaltados por triple filete (más ancho el central) que se prolongan hasta las tapas en forma triangular. En la parte central de los entrenervios se ha dispuesto un florón.

Decoración de las tapas. Dos orlas rectangulares concéntricas realizadas con distintas ruedas. La rueda exterior reproduce una escena corrida de caza (sobre un bosque de variada vegetación se identifican figuras a caballo en actitud de atacar; otras tocando un cuerno y variados animales). La rueda interior es de medallones de caras de perfil: unas con corona y otras con casco. Los medallones se enlazan con decoración vegetal. Las ruedas están delimitadas y unidas diagonalmente por las esquinas con triples filetes, más 
ancho el central. En las esquinas del rectángulo central aparecen florones. El eje central se decora en su mitad con un medallón ovalado con el monograma de Jesús acompañado de una cruz y tres clavos; y con hierros de caras de perfil con gorro en la parte superior e inferior. Entre la rueda exterior y el lomo hay un espacio vacío que se decora con florones situados a la altura de los entrenervios.

\subsection{Encuadernaciones decoradas con otros modelos de grecas}

46. Jansenius, Cornelius, Obispo de Gante. Cornelii Iansenii episcopi gandauensis commentariorum in suam Concordiam, ac totam Historiam Euangelicam partes IIII... Omnia iam denuò... ipsiusmet authoris opera quam accuratissimè repurgata... Lugduni: expensis Petri Landry, 1577.

T. 24037.

$36 \times 23 \times 8,5 \mathrm{~cm}$.

Encuadernación de piel color marrón claro sobre madera con vestigios de llevar broches. Técnica del gofrado.

El lomo pegado está formado por 4 nervios dobles que se prolongan hasta las tapas en forma triangular.

Las guardas son de papel verjurado, conservadas parcialmente.

Decoración de las tapas. Se inicia con una bordura de tres filetes (el central de hilo grueso). Le sigue un espacio vacío y a continuación una orla formada por rombos de hierros de cordelillo. Los espacios de los rombos se rellenan con cruces y pequeños círculos. La orla se entrecruza en las esquinas dando lugar a espacios rectangulares sin decorar. Esta orla está delimitada por tres filetes, el central de hilo ancho. En el espacio central se coloca un rectángulo con cuatro bandas longitudinales (ejecutadas con los mismos hierros de la orla) delimitadas con tres filetes, el central ancho. El rectángulo está separado de la orla por una entrecalle vacía y unida diagonalmente en las esquinas con tres filetes del mismo tipo.

47. Perault, Guillaume. Summae virtutum ac vitiorum tomus primus... Lugduni: apud Antonium Vincentium, 1554.

T. 85238 (2).

$16,5 \times 11 \times 7 \mathrm{~cm}$.

Encuadernación de piel color marrón sobre madera con vestigios de llevar broches de metal que no se conservan. Técnica del gofrado.

El lomo pegado está formado por 4 nervios sencillos resaltados por triple filete (más ancho el central) que apenas se aprecia por el desgaste.

Las cabezadas de un solo capitel van montadas al aire; están tejidas a mano y sujetas al libro en diferentes puntos con el hilo de la cabezada.

Las guardas son de papel verjurado. Se conservan parcialmente.

Decoración de las tapas. Cuatro bandas u orlas que forman rectángulos separados por finísimas entrecalles. En las esquinas al cruzarse los filetes se forman pequeños cuadrados. Las orlas están compuestas por balaustres y enmarcadas por filetes de un hilo. 
En el centro de la tapa se dispone una cartela ovalada que reproduce el monte calvario con las tres cruces, una calavera en el suelo árboles a los lados y el Santo Sepulcro. También se incluyen dos pequeños hierros de flor de lis por encima y por debajo de la cartela y otros hierros en forma de corazón atravesado por una flecha en las esquinas interiores.

\section{RESULTADOS Y CONCLUSIONES}

Este estudio ha permitido comprobar que la Biblioteca del Seminario Metropolitano de Badajoz cuenta con una notable colección de encuadernaciones artísticas. El periodo analizado corresponde a las encuadernaciones de mayor antigüedad. De los periodos posteriores el número de encuadernaciones conservadas es mayor, revelando un prometedor campo de estudio.

La decoración que predomina en los 47 ejemplares analizados teniendo en cuenta la clasificación empleada es la caracterizada por el uso de filetes y florones en sus dos variantes: con la técnica de gofrado y con la técnica del dorado (Tabla 1).

\begin{tabular}{|l|c|}
\hline Decoración & $\begin{array}{c}\mathbf{N}^{\mathbf{o}} \\
\text { ejemplares }\end{array}$ \\
\hline Filetes y florones gofrados & 10 \\
\hline Filetes y florones dorados & 12 \\
\hline Filetes gofrados a los que acompañan florones dorados & 2 \\
\hline Filetes gofrados y dorados, y florones gofrados y dorados & 1 \\
\hline Grecas de elementos vegetales & 9 \\
\hline Grecas de cabecitas encerradas en óvalos o en círculos & 10 \\
\hline Grecas de animales en movimiento o reposo entre elementos vegetales & 1 \\
\hline Otros modelos de grecas & 2 \\
\hline
\end{tabular}

Tabla 1. Distribución de las encuadernaciones según el tipo de decoración.

Uno de los elementos definitorios más significativos de la constitución del libro son los nervios. En este caso todas las encuadernaciones están realizadas con nervios salientes. Hay diferencias respecto al número de nervios, oscilando entre las encuadernaciones de 3 nervios y la de 6 . Siendo las más numerosas las de 4 y 5 nervios (Tabla 2). Se utilizan tanto nervios sencillos como dobles y todos los lomos van pegados, menos uno que es hueco.

\begin{tabular}{|l|l|}
\hline Tipo de lomo & $\mathbf{N}^{\mathbf{0}}$ de ejemplares \\
\hline De 3 nervios & 7 (en 4 son dobles, en 2 sencillos y en 1 no se aprecia) \\
\hline De 4 nervios & 22 (en 12 son dobles, en 5 son sencillos, en 5 no se aprecia) \\
\hline De 5 nervios & 14 (en 11 son dobles, en 3 no se aprecia) \\
\hline De 6 nervios & 4 (en 3 son dobles, en 1 son sencillos) \\
\hline
\end{tabular}

Tabla 2. Distribución de las encuadernaciones según el tipo de lomo. 
En cuanto al tipo material de las guardas existe gran coincidencia. De los 40 ejemplares que incluyen guardas, en 37 se han elaborado con papel verjurado. Papel realizado por un procedimiento manual que refleja la impronta de los hilos metálicos del tamiz con que se fabrica. En un ejemplar se aprecia que las guardas originales eran de papel jaspeado y se han sustituido por otras de papel estampado. En otros dos también han sido sustituidas por otras de papel más moderno.

A la vez hemos comprobado que sólo 7 ejemplares tienen hojas de respeto (hojas en blanco que van al inicio y/o al final del libro).

Los cortes han sido objeto de decoración en el caso de 19 ejemplares. Predomina la técnica del dorado con cincelado (Tabla 3).

\begin{tabular}{|c|c|c|}
\hline Técnica & $\begin{array}{c}\mathrm{N}^{\mathrm{o}} \\
\text { ejemplares }\end{array}$ & Ejemplares del catálogo \\
\hline Coloreados con tinta roja & 4 & $n^{\circ} 1, n^{\circ} 32, n^{\circ} 33, n^{\circ} 39$ \\
\hline Coloreados con tinta verde & 1 & $\mathrm{n}^{\circ} 24$ \\
\hline Coloreados con gotas de tinta roja & 1 & $\mathrm{n}^{\circ} 29$ \\
\hline Dorados & 1 & $\mathrm{n}^{\circ} 15$ \\
\hline Dorados y cincelados & 12 & $\begin{array}{l}n^{\circ} 11, n^{\circ} 12, n^{\circ} 13, n^{\circ} 14, n^{\circ} 16, n^{\circ} \\
18, n^{\circ} 19, n^{\circ} 25, n^{\circ} 21, n^{\circ} 22, n^{\circ} \\
20, n^{\circ} 23\end{array}$ \\
\hline
\end{tabular}

Tabla 3. Encuadernaciones con los cortes decorados.

Nos parece interesante indicar la iconografía más significativa que se plasma en los motivos decorativos de las encuadernaciones (Tabla 4). Dos temas son los que más se repiten el monograma de Cristo (JHM) acompañado de la cruz y los tres clavos, y el Cordero místico.

El primero relacionado con la orden de los jesuitas y el segundo inspirado en el Apocalipsis. 


\begin{tabular}{|c|c|c|c|}
\hline Iconografía & $\begin{array}{l}\text { Diseño / } \\
\text { herramienta }\end{array}$ & $\begin{array}{l}\mathrm{N}^{\mathrm{o}} \\
\text { ejemplare } \\
\mathrm{S}\end{array}$ & $\begin{array}{l}\text { Ejemplares del } \\
\text { catálogo }\end{array}$ \\
\hline Cordero místico & Hierros sueltos & 5 & $\begin{array}{l}\mathrm{n}^{\circ} 2, \mathrm{n}^{\circ} 5, \mathrm{n}^{\circ} 10, \mathrm{n}^{\circ} \\
26, \mathrm{n}^{\mathrm{o}} 35\end{array}$ \\
\hline $\begin{array}{l}\text { Monograma de Cristo } \\
(\mathrm{JHM}) \text { con cruz y tres clavos }\end{array}$ & Cartelas & 7 & $\begin{array}{l}n^{\circ} 3, n^{\circ} 8, n^{\circ} 26, n^{\circ} \\
34, n^{\circ} 35, n^{\circ} 36, n^{\circ} 45\end{array}$ \\
\hline $\begin{array}{l}\text { Monograma de la Virgen } \\
\text { María }\end{array}$ & Cartela & 1 & $n^{\circ} 36$ \\
\hline Escudo heráldico religioso & $\begin{array}{l}\text { Plancha en forma } \\
\text { de cartela }\end{array}$ & 1 & $\mathrm{n}^{\mathrm{o}} 11$ \\
\hline $\begin{array}{l}\text { Calvario (tres cruces, } \\
\text { árboles y calavera) }\end{array}$ & Cartela & 1 & $\mathrm{n}^{\circ} 4$ \\
\hline $\begin{array}{l}\text { Corazón rematado por cruz } \\
\text { y traspasado por dos flechas }\end{array}$ & Cartela & 1 & $\mathrm{n}^{0} 12$ \\
\hline $\begin{array}{lcr}\text { Calvario } & \text { (tres } & \text { cruces, } \\
\text { calavera, } & \text { árboles, } & \text { Santo } \\
\text { Sepulcro) } & & \\
\end{array}$ & Cartela & 1 & $n^{\circ} 47$ \\
\hline Cartela con las 5 llagas & Cartela & 1 & $\mathrm{n}^{\circ} 16$ \\
\hline Escena de la Anunciación & $\begin{array}{l}\text { Plancha en forma } \\
\text { de medallón }\end{array}$ & 1 & $\mathrm{n}^{\circ} 25$ \\
\hline
\end{tabular}

Tabla 4. Iconografía destacada de los motivos decorativos.

Del conjunto de encuadernaciones analizadas destacamos las 22 encuadernaciones clasificadas dentro del apartado "Encuadernaciones que emplean como principal motivo decorativo las grecas”, son una variada y muy significativa muestra del estilo plateresco, tan característico del arte ligatorio español. Si las diferenciamos según la disposición de su estructura (Méndez 1994, p. 98) tenemos estas variantes: las que presentan una sola orla ( $\left.n^{\circ} 31\right)$; las que tienen dos o más orlas paralelas entre sí y la cubierta, separadas por bandas ( ${ }^{\text {os }} 35$ a 45 ); las que presentan una orla separada de un rectángulo central por una entrecalle vacía de decoración, el rectángulo se cubre con la misma orla repetida longitudinalmente tres veces $\left(\mathrm{n}^{\circ} 46\right)$ y las que llevan orlas que adoptan la forma de figuras geométricas ( ${ }^{\text {os }} 32$ a 34), alguna de las cuales se puede considerar representativa del estilo popular ( $n^{\circ} 32$ ), considerado como un estilo de transición entre las encuadernaciones platerescas y las barrocas y que entre sus características se encuentran las cubiertas con grandes rombos, cuadrados o hexágonos centrales, rodeados por varias orlas rectangulares ${ }^{4}$.

Las encuadernaciones decoradas con grecas de cabecitas encerradas ( $n^{\text {os }} 35$ a 44) presentan diseños que guardan bastante parecido con otros ejemplares conservados en destacadas colecciones españolas. Para ilustrar estas semejanzas vamos a citar ejemplares recogidos en los siguientes catálogos Encuadernaciones españolas en la Biblioteca Nacional (1992); Encuadernaciones en la Biblioteca Complutense (2005); 
Encuadernaciones Artísticas: exposición virtual, Universidad de Navarra (2006); y en estos estudios Méndez (1994); Miguélez (2009a).

La encuadernación $n^{\circ} 31$ coincide con la 31 (Miguélez, Biblioteca U. Salamanca) en la disposición de una ancha orla formada por la repetición de una misma rueda gofrada en contraste con la ornamentación en dorado del espacio central realizada con hierros sueltos, dispuestos del mismo modo en las dos encuadernaciones. La encuadernación $\mathrm{n}^{\circ} 35$ es prácticamente idéntica a la 64 (Biblioteca Nacional). La n 36 guarda un estrecho parecido con la 43 (Miguélez, Biblioteca U. Salamanca). La $\mathrm{n}^{\circ} 41$ presenta la misma estructura compositiva que la 72 (Biblioteca Nacional) añadiendo una orla más. El parecido es mayor en la $\mathrm{n}^{\circ} 43 \mathrm{~b}$ respecto a la 70 (Biblioteca Nacional) y la no ${ }^{\circ}$ 43a con la 40 (Biblioteca U. Complutense). En estas dos sorprende el uso de los mismos hierros de delfines que imitan un monstruo para decorar el recuadro central de la tapa. La $\mathrm{n}^{\circ} 44$ caracterizada por las orlas concéntricas y si separación se identifica con la 58 (Biblioteca U. Complutense). $\mathrm{La}^{\circ}$ 45, aunque presenta una disposición en su decoración equivalente a otras como la 58 (Biblioteca Nacional) o la 52 (Méndez, Biblioteca Pública Burgos), sorprende por el motivo de la rueda con escenas de caza menos habitual.

Otras de las encuadernaciones estudiadas también se pueden considerar cercanas a la de los estudios citados: la encuadernación $\mathrm{n}^{\circ} 6$ destaca por la misma sencillez de la 2 (Miguélez, Salamanca SIG. Inc. 113) o la $\mathrm{n}^{\circ} 13$ (Miguélez, Biblioteca U. Salamanca) en las que la decoración se reduce prácticamente al motivo del centro de la tapa formado por la unión de varios hierros.

Las encuadernaciones $\mathrm{n}^{\text {os }} 8$ y 9 son muy semejantes a la 89 (Biblioteca U. Complutense) procedente de los Reales Estudios de San Isidro. La $\mathrm{n}^{\circ} 26$ coincide con la 53 (Méndez, Biblioteca Pública Toledo) en el superlibris, en el número y la disposición de los hierros y ruedas, pero difieren en los motivos de ambos. Un parecido mayor es el que guarda la no 30 con la 99 (Biblioteca U. Complutense). Sólo se ve diferencia en el hierro que decora el centro de la tapa, en la primera es un león rampante con otro hierro sobrepuesto en forma de cruz y en la segunda un escudo eclesiástico. La $\mathrm{n}^{\circ} 34$ se ha diseñado empleando un trazado de las orlas como la FA 133.125 (Biblioteca U. Navarra), pero ésta presenta un modelo más sobrio sin el uso de hierros sueltos y con unas orlas diferentes. La encuadernación $\mathrm{n}^{\circ} 25$ desprende cierta semejanza con la FA 135.159 (Biblioteca U. Navarra) por el empleo de filetes gofrados y dorados y por el motivo central realizado con una plancha en dorado.

Respecto a la encuadernación número $n^{\circ} 46$ queremos matizar que la estructura decorativa se da en encuadernaciones renacentistas, por ejemplo, aparece en las encuadernaciones 65 y 71 (Biblioteca Nacional), en la 100 (Biblioteca U. Complutense) o en la 46 (Miguélez, Biblioteca U. Salamanca), pero la decoración de las ruedas con rombos de hierros de cordelillo es propia del estilo gótico. Así se considera en la encuadernación 19 (Biblioteca U. Complutense). 
Como diseños originales, además de los ya mencionados en los anteriores comentarios, señalamos las encuadernaciones $n^{\text {os }} 32$ y 34 por los cuidados diseños de grecas que forman figuras completadas por una armoniosa combinación de hierro sueltos; la encuadernación n 23 de la que nos sorprende la parte central colocada a modo de placa, realizada en dorado con una personalizada decoración plateresca; y la encuadernación $n^{\circ}$ 25 por la elegante combinación de filetes en dorado y gofrado y por la plancha central la convierten en un modelo único dentro del conjunto de las conservadas en la Biblioteca.

Finalmente queremos hacer incidencia en que esta investigación nos ha permitido comprobar que son necesarias medidas de conservación y de restauración para preservar estas encuadernaciones. En la Biblioteca del Seminario el fondo antiguo está mezclado con el moderno, colocado en estanterías, sometido a continuos roces y acumulación de polvo. Por lo que, en gran parte, ha llegado a nuestros días con manifiestas muestras de deterioro. Entre las principales alteraciones detectadas podemos mencionar pérdidas superficiales de la piel, deterioro en los bordes y esquinas de las cubiertas, deshidratación (sobre todo en los lomos) y manchas de humedad.

\section{NOTAS}

1. Para más información véanse los siguientes trabajos de Pérez (2007); Tejada (2007); Tejada y Pérez (2007, 2008, 2009 y 2010).

2. Respecto la normalización para la descripción de las encuadernaciones no existe una uniformidad. Ante esta ausencia de normalización detallada los propios autores e investigadores, relacionados con el estudio de las encuadernaciones, han elaborado sus propios modelos de fichas descriptivas. Destacamos las recomendaciones para la redacción de asientos descriptivos de encuadernaciones elaboradas por Carpallo (1999 y 2002).

3. La mayoría de las definiciones las hemos obtenido de la Enciclopedia de la Encuadernación (1998).

4. Para más información se pueden consultar los trabajos de Crespí (2000) y Carrión (1992 y 1994).

5. Para referirnos a las diferentes encuadernaciones de estos trabajos las citamos utilizando el número o referencia con los que aparecen en el trabajo correspondiente. Añadiendo entre paréntesis, para los catálogos, el nombre de la Biblioteca y también el primer apellido del autor para los estudios.

\section{BIBLIOGRAFÍA}

CARPALLO BAUTISTA, A. (2002). Análisis documental de la encuadernación española: repertorio bibliográfico, tesauro y ficha descriptiva. Madrid: AFEDA, 2002.

(1999). La encuadernación y su descripción. Boletín de la ANABAD, 1999, eneromarzo, vol. 1, p. 227-236.

CARRIÓN GÚTIEZ, M. (1992). La encuadernación artística española. Encuadernaciones españolas de la Biblioteca Nacional. Madrid: Biblioteca Nacional, Julio Ollero, editor.

(1994). La encuadernación española en los siglos XVI, XVII y XVIII. En Historia ilustrada del libro español. De los incunables al siglo XVIII. Madrid: Fundación Germán Sánchez Ruipérez, p. 395-445.

CRESPÍ DE VALLDAURA, L. (2000). Las ejecutorias y sus encuadernaciones. En El documento pintado: cinco siglos de arte en manuscritos. Madrid: Ministerio de Educación y Cultura, p. 87-98. 
Enciclopedia de la Encuadernación (1998). Madrid: Ollero \& Ramos, p. 234. Voz: Plateresco.

Encuadernaciones en la Biblioteca Complutense (2005). Madrid: Servicio de Publicaciones de la Universidad.

Encuadernaciones artísticas. Exposición virtual: 1 de abril-30 de junio de 2006 (2006) < http://dspace.unav.es/dspace/html/10171/4028/hufaexp09p-01.html>. [Consulta: 20/06/2011].

Encuadernaciones españolas en la Biblioteca Nacional (1992). Madrid: Biblioteca Nacional.

LÓPEZ SERRANO, M. (1972). La encuadernación española. Breve historia. Madrid: ANABA (Asociación Nacional de Bibliotecarios Archiveros y Arqueólogos).

MÉNDEZ APARICIO, J. (1994). Las encuadernaciones de los siglos XV y XVI. En Creadores del libro. Del Medievo al Renacimiento: Sala de exposiciones de la Fundación Central Hispano: 28 de septiembre-20 de noviembre, 1994. Madrid: Dirección General del Libro y Bibliotecas: Fundación Central Hispano, p. 89-110.

MIGUÉLEZ GONZÁLEZ, E.J. (2009a). La encuadernación artística de la Biblioteca histórica de la Universidad de Salamanca: estilos y técnicas. Salamanca: Universidad de Salamanca. Colección Vitor 232. Tesis doctorales.

(2009b). El influjo renacentista en las encuadernaciones de la Biblioteca Histórica de la Universidad de Salamanca. Anales de Documentación, 2009, n 12, p. 181-208.

PÉREZ ORTIZ, G. (2007). La biblioteca del Seminario Metropolitano de San Atón de Badajoz: la mejor colección religiosa de Extremadura. Mi biblioteca: la revista del mundo bibliotecario, 2007, nº 8, p. 105-112.

TEJADA VIZUETE, F. (2007). La Biblioteca del Seminario Metropolitano San Atón de Badajoz. Vitela, 2007, n 10 , p. 4-8.

TEJADA VIZUETE, F. y PÉREZ ORTIZ, G. (2007). La biblioteca del Seminario Metropolitano de Badajoz (I). Libros del siglo XVI impresos en España. Pax et Emerita. Revista de Teología y Humanidades de la Archidiócesis de Mérida-Badajoz, 2007, vol. 3, p. 275-444.

(2008). La biblioteca del Seminario Metropolitano de Badajoz (II). Libros del siglo XVI impresos en Lyon. Pax et Emerita. Revista de Teología y Humanidades de la Archidiócesis de Mérida-Badajoz, 2008, vol. 4, p. 409-475.

(2009). La biblioteca del Seminario Metropolitano de Badajoz (III). Libros del siglo XVI impresos en París y Amberes. Pax et Emerita. Revista de Teología y Humanidades de la Archidiócesis de Mérida-Badajoz, 2009, vol. 5, p. 291-348.

(2010). La biblioteca del Seminario Metropolitano de Badajoz (IV). Libros del siglo XVI impresos en Italia. Pax et Emerita. Revista de Teología y Humanidades de la Archidiócesis de Mérida-Badajoz, 2010, vol. 6, p. 497-555. 